\title{
Thermoplastic Waxy Starch Films Processed by Extrusion and Pressing: Effect of Glycerol and Water Concentration
}

\author{
Anderson Felix Manoel ${ }^{a *}$, Pedro Ivo Cunha Claro ${ }^{b}$, Luiz Henrique Capparelli Mattoso ${ }^{c}$, José Manoel \\ Marconcini ${ }^{c}$, Gerson Luiz, Mantovani ${ }^{a}$ \\ ${ }^{a}$ Universidade Federal do ABC - UFABC, Avenida dos Estados, 5001, CEP 09210-580, Santo André, SP, Brazil. \\ ${ }^{b}$ Universidade Federal de São Carlos - UFSCar, Rodovia Washington Luiz, km 235 - P.O. Box 676, CEP \\ 13565-905, São Carlos, SP, Brazil. \\ ${ }^{c}$ Laboratório Nacional de Nanotecnologia Aplicada para o Agronegócio - LNNA, Embrapa \\ Instrumentação, Rua XV de Novembro, 1452, CEP 13560-970, São Carlos, SP, Brazil.
}

Received: November 26, 2016; Revised: July 11, 2017; Accepted: July 27, 2017

\begin{abstract}
Thermoplastic starch properties depends of plastification process. The aim of this study was to analyze the effect of concentration of glycerol and water on plastification, glass transition temperature $\left(\mathrm{T}_{\mathrm{g}}\right)$ and tensile properties of thermoplastic waxy starch (TPWS). Formulations were extruded in the following concentrations of starch/glycerol/water: 70/30/0 (TPWS 0\%); 70/25/5 (TPWS 5\%); 70/20/10 (TPWS 10\%) weight percentage. Crystalline peaks in WAXS diagrams and native grains present in SEM micrographs showed that the TPWS $0 \%$ and $5 \%$ were not sufficient to promote total plastification of the waxy starch, and TPWS $10 \%$ showed the higher starch plastification. $\mathrm{T}_{\mathrm{g}}$ measurements by DMTA were $30{ }^{\circ} \mathrm{C}$ to TPWS $0 \%, 23{ }^{\circ} \mathrm{C}$ to TPWS $5 \%$ and $40{ }^{\circ} \mathrm{C}$ to TPWS $10 \%$. These results showed that glycerol and water had effect plasticizer in TPWS 5\% and antiplasticizer in TPWS 10\%. Mechanical tensile results showed that higher tensile strength was observed in the systems with more effective starch plastification.
\end{abstract}

Keywords: waxy starch, plastification process, plasticizer effect, films, extrusion.

\section{Introduction}

Starch is a carbohydrate present in abundance on the environment, which has advantages over others biodegradable polymers such as low cost and biologically absorbable ${ }^{1}$. Starch consists of two major components, the linear amylose and the highly branched amylopectin ${ }^{2,3}$. There are three types of starch wherein the amylose concentration ranges: native starch (15-30 wt \% amylose); waxy starch (0-5 wt\% amylose); and high amylose starch $(35-70 \mathrm{wt} \% \text { amylose })^{2,3}$.

Native starch is not processible and this drawback can be resolved by plastification process ${ }^{4-6}$. When starch is mixed with plasticizers under shear rate and temperature between 90-180 ${ }^{\circ} \mathrm{C}$ their amylose/amylopectin chains are interspersed, and the amylopectin structure original is destroyed. This material is called starch thermoplastic (TPS $)^{7,8}$.

The type and concentration of plasticizer employed has significant effect on the plastification process, glass transition temperature $\left(\mathrm{T}_{\mathrm{g}}\right)$ and mechanical properties ${ }^{6,9-12}$. Theoretically, plastification process consists essentially in altering the viscosity of the system, in which the material becomes processable. Plasticizers add to the polymer affect all its plastificaton process, physical and mechanical

*e-mail: andersonfelixmanoel@gmail.com properties. Plasticizer effect is characterized by a drop in $\mathrm{T}_{g}$ and antiplasticizer effect is characterized by a grow in $\mathrm{T}_{\mathrm{g}}{ }^{13}$.

The most commons plasticizers utilized for starch are polyols such as glycerol. However, the addition of polyols decreases film mechanical resistance ${ }^{4}$. Recent study has shown it was found that plastification process of waxy starch ( $\sim 99 \mathrm{wt} \%$ amylopectin) were more easily performed than native starch $(72 \%$ amylopectin and $28 \%$ amylose $)^{14}$.

In this work, we proposed to investigate the effect of glycerol and water concentration on plastification, glass transition temperature $\left(\mathrm{T}_{\mathrm{g}}\right)$ and tensile properties of thermoplastic waxy starch (TPWS) films processed by extrusion and pressing. Many works in the literature deal with plasticization of the waxy starch with several polyols, without focusing on the variation of the amount of water together with polyols in the plastification process, mechanical properties and plasticizer effect ${ }^{15}$.

\section{Experimental}

\subsection{Materials}

The following materials were used: waxy corn starch (Amidex $^{\circledR} 4001$ from Ingredion ${ }^{\circledR}$ with approximately 100 wt $\%$ amilopectin ; glycerol from Nitrogenius ${ }^{\circledR}$; distilled water; 
stearic acid $(\mathrm{MW}=284.48 \mathrm{~g} / \mathrm{mol})$ from $\mathrm{Vetec}^{\circledR}$; and citric acid $(\mathrm{MW}=192.13 \mathrm{~g} / \mathrm{mol})$ from $\mathrm{Chemco}^{\circledR} 99.5 \%$ of purity.

\subsection{Preparation of film formulations and film processing}

Waxy starch was mixed with different amounts of glycerol and water. The samples compositions are shown in Table 1. It was added citric acid ( $1 \mathrm{wt} \%)$, and stearic acid (1 wt \%) in all samples compositions. Citric and stearic acids were used as processing auxiliaries.

Table 1. Thermoplastic waxy starch films compositions.

\begin{tabular}{cccc}
\hline Films & $\begin{array}{c}\text { Waxy starch } \\
{[\mathrm{wt} \%]}\end{array}$ & $\begin{array}{c}\text { Glycerol } \\
{[\mathrm{wt} \%]}\end{array}$ & Water [wt\%] \\
\hline TPWS 0\% & 70 & 30 & 0 \\
TPWS 5\% & 70 & 25 & 5 \\
TPWS 10\% & 70 & 20 & 10 \\
\hline
\end{tabular}

The TPWS compositions were plasticized in a co-rotating twin-screw extruder (Coperion $18 \mathrm{~mm}$ and $\mathrm{L} / \mathrm{D}=40$ ). The materials were added into the feed at screw rotation speed of $300 \mathrm{rpm}$ twin screw profile of high shear. The temperature profile of the feed channel to the matrix was $110,120,120$, $125,130,135$, and $140^{\circ} \mathrm{C}$. After the extrusion process pellets were obtained, which were pressed (by initial pressing of 3.0 tons, and final pressing of 5.0 tons per minute each at a temperature of $140{ }^{\circ} \mathrm{C}$ with subsequent cooling under pressing of 5.0 tons). Films obtained with a thickness of about $200 \mu \mathrm{m}$ are shown in Figure 1.

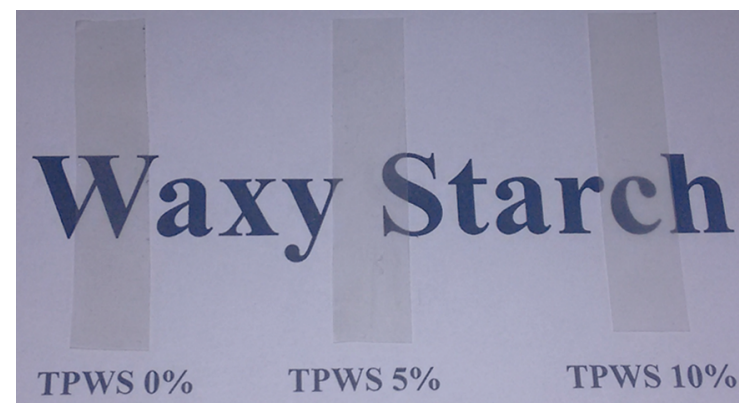

Figure 1. Films of TPWS 0\%, TPWS 5\%, and TPWS 10\%.

\subsection{Morphological analysis}

The cross-section of the films obtained from cryogenic fracture was analyzed by micrographs obtained from a scanning electron microscope (SEM), model JMS 6510 $\left(\mathrm{JEOL}^{\circledR}\right)$, using an accelerating voltage of $10 \mathrm{kV}$. Samples were mounted on copper stubs, and then coated with gold.

\section{$2.4 X$-ray diffraction $(X R D)$}

The diffractograms were recorded on a LabX XRD 6000 Shimadzu ${ }^{\circledR}$ diffractometer operating at $30 \mathrm{kV}, 30 \mathrm{~mA}$ and $\mathrm{CuK} \alpha$ radiation $(\lambda=1540 \AA)$. The samples were scanned in
2-Theta ranges varying from 10 to $40^{\circ}$ and the scan speed employed was $0.5^{\circ} \mathrm{min}^{-1}$.

\subsection{Mechanical properties}

Uniaxial tensile tests of films were performed in a universal testing machine EMIC ${ }^{\circledR}$ according to ASTM D $882-12^{16}$ at a speed of $0.5 \mathrm{~mm} / \mathrm{min}$ with a $10 \mathrm{kgf}$ load cell at $25^{\circ} \mathrm{C}\left( \pm 2{ }^{\circ} \mathrm{C}\right), 50 \mathrm{~mm}$ distance between the jaws, and a relative humidity $(\mathrm{RH})$ of $50 \%( \pm 5 \%)$. The Young's modulus, tensile strength, and strain at break were evaluated.

\subsection{Dynamic mechanical thermal analysis (DMTA)}

Dynamic mechanical thermal analysis (DMTA) was performed in a model Q800 (TA Instruments equipment ${ }^{\circledR}$ ), using tension-film geometry in the range $-50{ }^{\circ} \mathrm{C}$ to $70{ }^{\circ} \mathrm{C}$, at the scanning rate of $2{ }^{\circ} \mathrm{C} / \mathrm{min}$ and constant frequency of $1 \mathrm{~Hz}$. Samples were conditioned at $25^{\circ} \mathrm{C}$ and $30 \% \mathrm{RH}$ for 48 hours. The glass transition temperature $\left(\mathrm{T}_{\mathrm{g}}\right)$ was defined on the $\tan \delta$ broad peak.

\section{Results and Discussion}

\subsection{Morphological analysis}

Figure 2 presents cross-section cryogenic fracture by SEM for TPWS $0 \%, 5 \%$ and $10 \%$.

SEM micrographs showed that TPWS $0 \%$ composition exhibits some native or partly melted starch granules spread over the film indicated by white arrows (Figure $2 b$ ). The grains with diameter around one micron show that they were broken in the extrusion process. On the other hand, SEM micrographs also showed that the compositions with the addition of water exhibit less native starch granules, suggesting that water is an excellent agent for plastification (Figure 2c to $2 \mathrm{f}$ ). Some points observed for TPWS 5\% and $10 \%$ can be bubbles that caused due to presence of water.

The study about TPS films shows that the number and size of these granules grow up with increasing concentration of plasticizer such as glycerol. The complete plastification of starch under low moisture conditions in the extruder required application of a considerable amount of shear, which was not feasible in the presence of glycerol ${ }^{17}$.

\section{$3.2 X$-ray diffraction $(X R D)$}

Figure 3 has shown X-ray diffraction patterns for waxy starch, TPWS $0 \%$, TPWS 5\%, and TPWS $10 \%$. Waxy starch shows a typical A-type pattern, with strong reflections at $2 \theta$ about $15^{\circ}$ and $23^{\circ}$, and an unresolved doublet at $17^{018}$. An amorphous state was observed in the thermoplastic waxy starch film with $10 \%$ glycerol $^{19}$. The single peak at $2 \theta 21^{\circ}$ that occurs for this composition is the retrogradation of waxy $\operatorname{starch}^{20}$. For compositions, TPWS $0 \%$ and TPWS $5 \%$ are possible to observe 


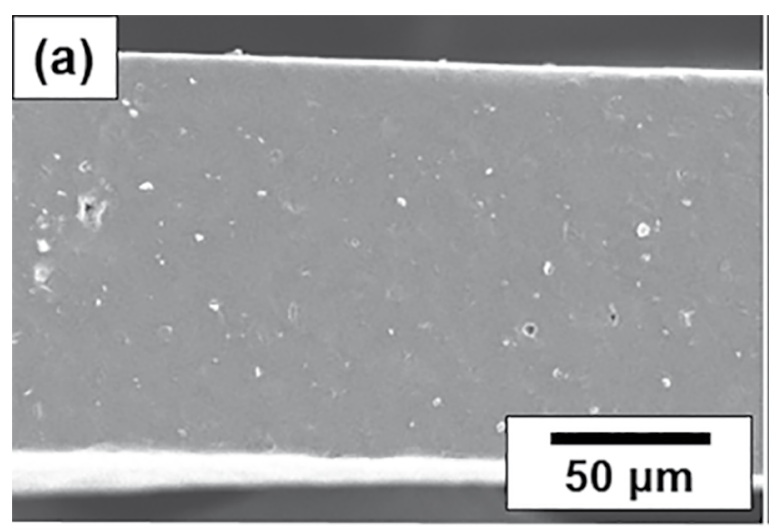

(b)
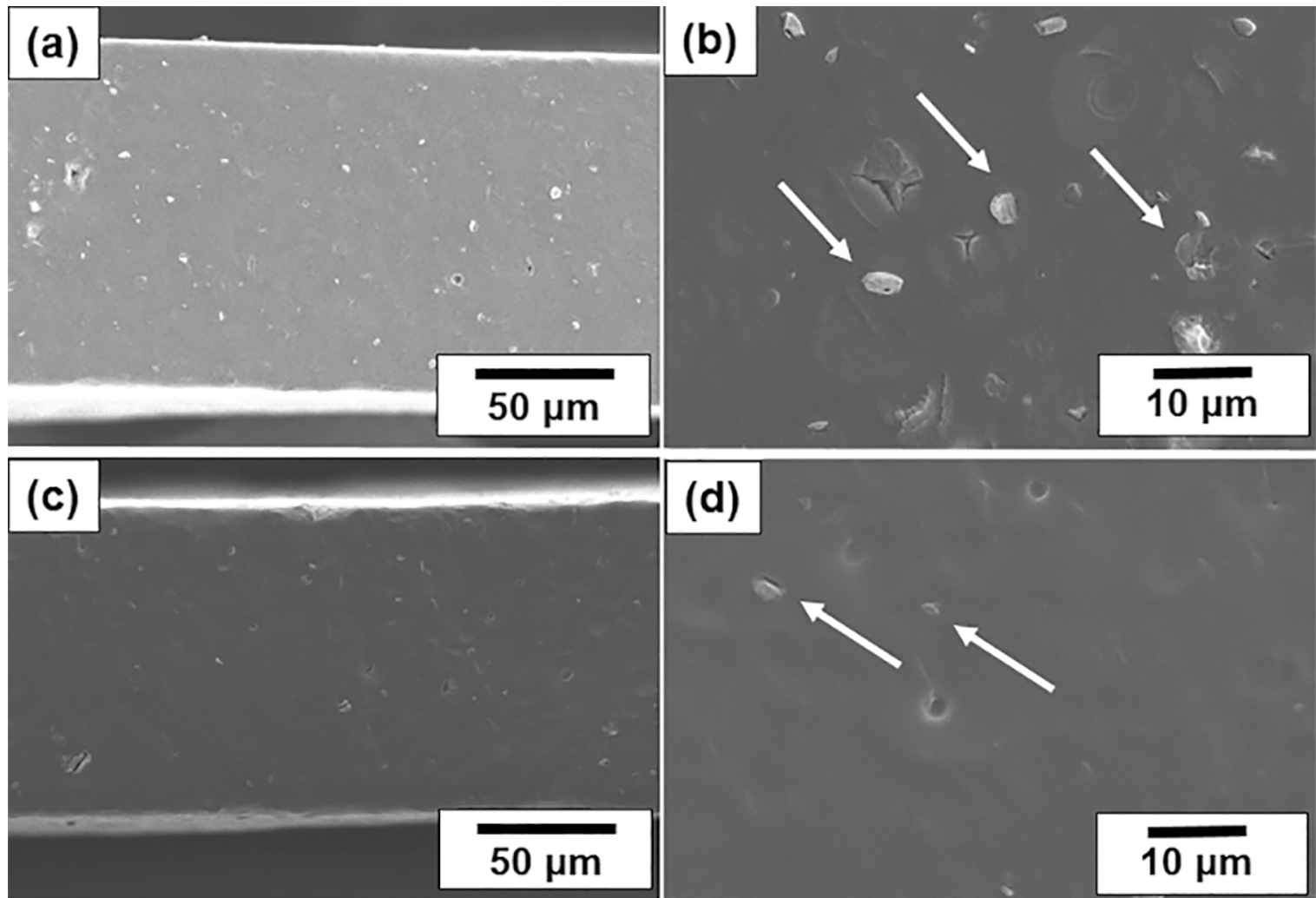

\section{(d)}
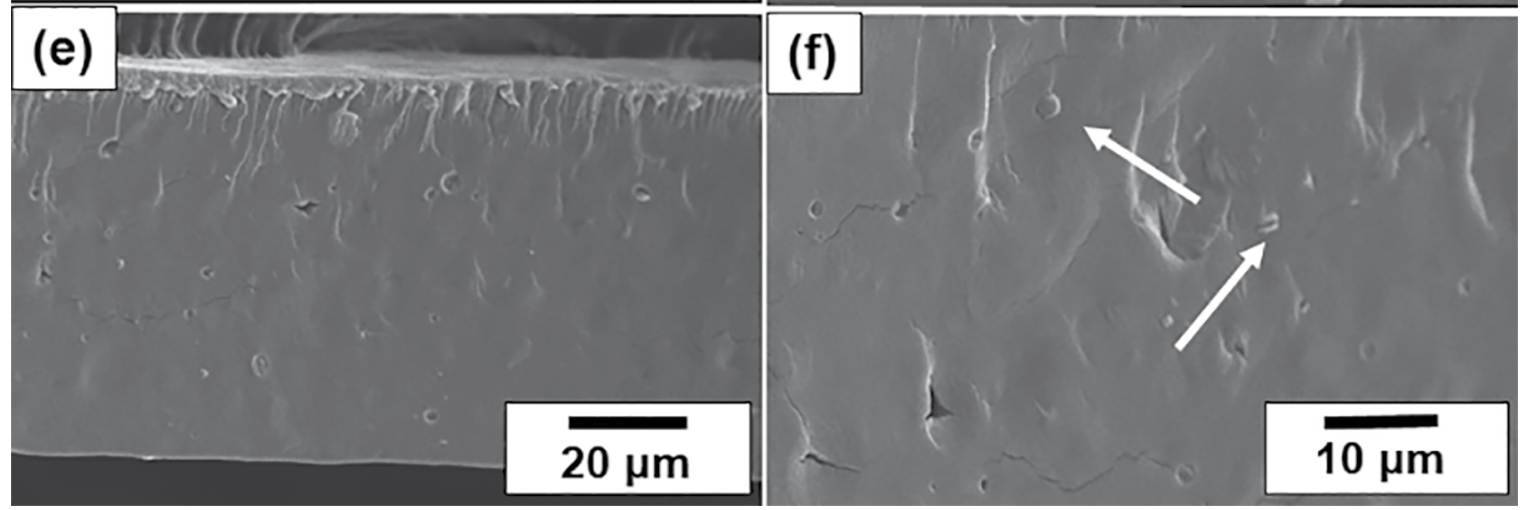

Figure 2. (a) SEM micrographs of TPWS $0 \%$, (b) TPWS 5\%, and (c) - TPWS 10\%.

peaks characteristic of the waxy starch crystallinity, indicating that not occurred an efficient plastification for these compositions. The peaks characteristic of the waxy starch in the TPWS $0 \%$ and $5 \%$ compositions are according to Figure $2 a$ and $2 b$, where it is possible to see the starch in the form of grains. The diffractograms prove the plastification effect of the water in the process of extrusion of the waxy starch to transform it into thermoplastic waxy starch, with less quantity of native starch grains (Figure 2c).

\subsection{Dynamic mechanical thermal analysis (DMTA)}

Figure 4 shows the curves of storage tensile modulus $\left(\mathrm{E}^{\prime}\right)$ and damping factor $(\tan \delta)$ versus temperature, which

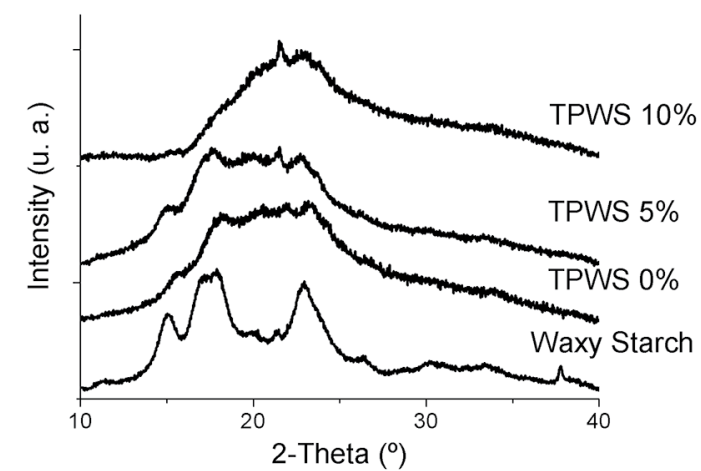

Figure 3. X-ray diffraction patterns for waxy starch, TPWS $0 \%$, TPWS 5\%, and TPWS $10 \%$. 

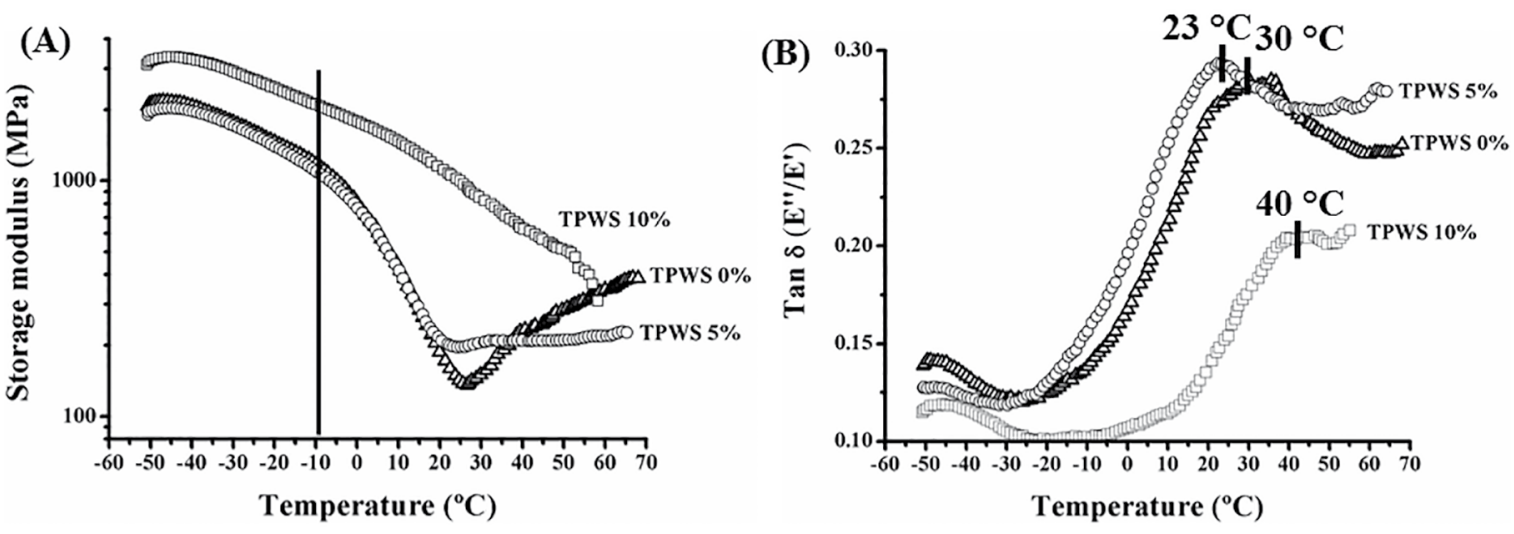

Figure 4. (a) Tensile storage modulus $E^{\prime}$ versus temperature, and (b) Damping factor $\tan \delta$ versus temperature for TPWS $0 \%$, TPWS $5 \%$, and TPWS $10 \%$

the decay for $\mathrm{E}^{\prime}$ correspond to $\tan \delta$ peak. The $\delta$ peak corresponded molecular relaxation or glass transition temperature $\left(\mathrm{T}_{\mathrm{g}}\right)$ of TPWS films that is affected by glycerol and water concentration.

$\mathrm{T}_{\mathrm{g}}$ measurements by DMTA were $30{ }^{\circ} \mathrm{C}$ to TPWS $0 \%$, $23{ }^{\circ} \mathrm{C}$ to TPWS $5 \%$ and $40{ }^{\circ} \mathrm{C}$ to TPWS $10 \%$. These results showed that glycerol and water had effect plasticizer in TPWS 5\% and antiplasticizer in TPWS $10 \%$.

The addition of glycerol in starch films provides more active sites by exposing its hydrophilic hydroxyl groups in which the water molecules could be adsorbed that exerted a plasticizing effect ${ }^{21,22}$. On the other hand, the addition of more water and removal of more glycerol causes the opposite effect, in which there is an increase in the interaction of the polymer chains, causing the antiplasticizer effect ${ }^{13}$.

The mechanical tensile test was performed at a temperature close to the $\mathrm{T}_{\mathrm{g}}$ of TPWS $5 \%$, in which it is not possible to observe the mechanical tensile plasticizer and antiplasticizer effect for this composition. Black line at $-10{ }^{\circ} \mathrm{C}$ on $\mathrm{E}^{\prime}$ diagrams, we observed the smallest Young's modulus for TPWS 5\%, showing the mechanical plasticizing effect for this composition ${ }^{13}$.

\subsection{Mechanical properties}

Table 2 shows the results of mechanical tensile properties. The tensile strength and Young's modulus grow, while strain at rupture diminishes when add water and decrease the amount of glycerol. These results prove that the effective plastification effect with water improved the mechanical properties, as seen in SEM micrographs and WAXS diagrams.

As the mechanical test was performed below the $\mathrm{T}_{g}$ of TPWS $10 \%$ it is possible to observe the antiplasticizer effect on the mechanical properties for this composition. The phenomenon antiplasticization occurs for TPWS when the Young's modulus and tensile stress grow, while strain at rupture diminishes in relation to others compositions ${ }^{13}$. When there is an increase in the amount of water into the
Table 2. Young's modulus, tensile strength, and strain at rupture of the films.

\begin{tabular}{cccc}
\hline Films & $\begin{array}{c}\text { Tensile } \\
\text { strength } \\
(\mathrm{MPa})\end{array}$ & $\begin{array}{c}\text { Young's } \\
\text { modulus } \\
(\mathrm{MPa})\end{array}$ & $\begin{array}{c}\text { Strain at rupture } \\
(\%)\end{array}$ \\
\hline TPWS 0\% & $5.0( \pm 0.7)$ & $218.9( \pm 27.4)$ & $0.062( \pm 0.018)$ \\
TPWS 5\% & $7.5( \pm 0.5)$ & $360.4( \pm 49.6)$ & $0.051( \pm 0.012)$ \\
TPWS 10\% & $9.2( \pm 0.2)$ & $704.4( \pm 80.8)$ & $0.024( \pm 0.001)$ \\
\hline
\end{tabular}

starch network, direct interactions and the proximity between starch chains were increased, thus under tensile forces, movements of starch chains were reduced, increasing $T_{g}$ and Young's modulus ${ }^{21-23}$.

\section{Conclusions}

We conclude that only the addition of glycerol was not effective for the total deconstruction of native starch grain and semicrystalline amylopectin structure as seen in SEM images and crystallinity peaks on WAXS diagrams. The water helped the destruction of native starch grains and semicrystalline amylopectin structure, showing an effective plastification process. Mechanical tensile results showed that higher tensile strength and Young's modulus were observed in the systems with more effective starch plastification. Glycerol and water had effect plasticizer in TPWS 5\% and antiplasticizer in TPWS $10 \%$, proving the effect of the amount of glycerol and water in $\mathrm{T}_{\mathrm{g}}$.

\section{Acknowledgements}

The authors are grateful for the support provided by CAPES, PPG-NMA/UFABC, PPGCEM/UFSCar and EMBRAPA Instumentation. This work is within the scope of the scientific-technological agreement between Federal University of ABC (UFABC) and Brazilian Agricultural Research Corporation (EMBRAPA), according to agreement number 23006.001234/2014-23. 


\section{References}

1. Famá LM, Goyanes S, Pettarin V, Bernal CR. Mechanical Behavior of Starch-Carbon Nanotubes Composites. In: Kar KK, Pandey JK, Rana SK, eds. Handbook of Polymer Nanocomposites Processing, Performance and Application. Volume B: Carbon Nanotube Based Polymer Composites. New York: Springer; 2015. p. 141-171.

2. Moad G. Chemical modification of starch by reactive extrusion. Progress in Polymer Science. 2011;36(2):218-237.

3. Gao J, Vasanthan T, Hoover R, Li JH. Structural modification of waxy, regular, and high-amylose maize and hulless barley starches on partial acid hydrolysis and their impact on physicochemical properties and chemical modification. Starch. 2012;64(4):313-325.

4. Talja RA, Helén H, Roos YH, Jouppila K. Effect of various polyols and polyol contents on physical and mechanical properties of potato starch-based films. Carbohydrate Polymers. 2007;67(3):288-295.

5. Vieira MGA, da Silva MA, dos Santos LO, Beppu MM. Naturalbased plasticizers and biopolymer films: A review. European Polymer Journal. 2011;47(3):254-263.

6. Sanyang ML, Sapuan SM, Jawaid M, Ishak MR, Sahari J. Effect of Plasticizer Type and Concentration on Tensile, Thermal and Barrier Properties of Biodegradable Films Based on Sugar Palm (Arenga pinnata) Starch. Polymers. 2015;7(6):1106-1124.

7. Avérous L. Biodegradable Multiphase Systems Based on Plasticized Starch: A Review. Journal of Macromolecular Science, Part C: Polymer Reviews. 2004;44(3):231-274.

8. Corradini E, Teixeira EdM, Agnelli JAM, Mattoso LHC. Amido termoplástico. São Carlos: Embrapa Instrumentação Agropecuária; 2007.

9. Zhong Y, Li Y. Effects of glycerol and storage relative humidity on the properties of kudzu starch-based edible films. Starch. 2014;66(5-6):524-532.

10. Aguirre A, Borneo R, León AE. Properties of triticale protein films and their relation to plasticizing-antiplasticizing effects of glycerol and sorbitol. Industrial Crops and Products. 2013;50:297-303

11. Razavi SMA, Amini AM, Zahedi Y. Characterisation of a new biodegradable edible film based on sage seed gum: Influence of plasticiser type and concentration. Food Hydrocolloids. 2015;43:290-298.
12. Smits ALM, Kruiskamp PH, Van Soest JJG, Vliegenthart JFG. Interaction between dry starch and plasticisers glycerol or ethylene glycol, measured by differential scanning calorimetry and solid state NMR spectroscopy. Carbohydrate Polymers. 2003;53(4):409-416.

13. Tager A. Physical Chemistry of Polymers. Moscow: Mir Publishers; 1978.

14. Li J, Luo X, Lin X, Zhou Y. Comparative study on the blends of PBS/thermoplastic starch prepared from waxy and normal corn starches. Starch. 2013;65(9-10):831-839.

15. Mathew AP, Dufresne A. Plasticized Waxy Maize Starch: Effect of Polyols and Relative Humidity on Material Properties. Biomacromolecules. 2002;3(5):1101-1108.

16. ASTM International. ASTM D882-12 - Standard Test Method for Tensile Properties of Thin Plastic Sheeting. West Conshohocken: ASTM International; 2012.

17. Pushpadass HA, Marx DB, Hanna MA. Effects of Extrusion Temperature and Plasticizers on the Physical and Functional Properties of Starch Films. Starch. 2008;60(10):527-538.

18. Cheetham NWH, Tao L. Variation in crystalline type with amylose content in maize starch granules: an X-ray powder diffraction study. Carbohydrate Polymers. 1998;36(4):277-284.

19. Xu YX, Kim KM, Hanna MA, Nag D. Chitosan-starch composite film: preparation and characterization. Industrial Crops and Products. 2005;21(2):185-192.

20. Kim JO, Kim WS, Shin MS. A Comparative Study on Retrogradation of Rice Starch Gels by DSC, X-Ray and ?-Amylase Methods. Starch. 1997;49(2):71-75.

21. García MA, Martino MN, Zaritzky NE. Edible starch films and coatings characterization: scanning electron microscopy, water vapor, and gas permeabilities. Scanning. 1999;21(5):348-353.

22. García MA, Martino MN, Zaritzky NE. Microstructural Characterization of Plasticized Starch-Based Films. Starch. 2000;52(4):118-124.

23. Mali S, Grossmann MVE, García MA, Martino MN, Zaritzky NE. Effects of controlled storage on thermal, mechanical and barrier properties of plasticized films from different starch sources. Journal of Food Engineering. 2006;75(4):453-460. 